\title{
LUNG DISEASE DUE TO INHALED DUST
}

\author{
By K. M. A. PerRy, M.D., F.R.C.P. \\ Physician to the London and Royal Masonic Hospitals
}

There is gradual realization that there is a severe air pollution in the industrial areas of the world and that this is a danger to the communities that live in them. In the week following the dense fog on December 8, 1952, there were 4,000 deaths in excess of those usual for the time of year, and these were attributed to acute bronchitis and its complications, resulting from the inhalation of the dioxide and trioxide of sulphur extruded by factory and domestic chimneys (Beaver Report, I954). The air pollution of cities is constantly present and the noxious substances are by no means confined to the oxides of sulphur. The concentrations may sometimes be higher in the factory than in the city atmosphere. These lesser concentrations certainly play an important part in the causation of chronic bronchitis and its resultant emphysema and cor pulmonale, the death rate for these diseases being 1,600 per million in Merseyside, compared with 600 per million in East Anglia and Hampshire. It is, therefore, evident that strenuous efforts should be made to control fume and thus reduce air pollution, which produces disease in the whole community. This is essentially industrial in origin, though it is not always classified as industrial disease.

\section{Dust Diseases}

It has been known since prehistoric times th at dust will produce diseases of the lung. It must be of a particle size of less than $5 \mu$ to pass through the smallest bronchioles and reach the alveoli. Some dusts are inert and, therefore, produce no tissue reaction in the lungs. They are important, however, since they may be radio-opaque and, according to their atomic weight, produce shadows in radiographs - these often cause alarm to patients and even doctors. Other dust will cause fibrosis and this disease has been called pneumonoconiosis (Greek: pneumon, lung; konis, dust), a word sometimes incorrectly abbreviated to pneumoconiosis. Yet other dusts will produce either a sensitivity or inflammatory reaction. A few more have been proved to be carcinogens and to contribute to the great increase in the incidence of carcinoma of the lung. In I900 there were $273 \frac{\circ}{\circ}$ deaths in England and Wales from this condition; in 1920, 500; and in 1955, 17,272. It is possible that the part played by air pollution is greater than is at present realized.

\section{Inert Dusts}

The most important dust to cause X-ray 응 shadowing is iron oxide. It occurs commonly in industry: welders, oxy-acetylene cutters, polishers, tool makers, cutlery makers, foundry workers and haematite miners have considerable exposure. The क last two occupations involve exposure to a mixed $\vec{\theta}$ dust, including silica, and in consequence silicosis fo is a recognized risk in these occupations. The radiological shadowing in siderosis is discrete ant nodular. The condition produces no symptoms, and it has been shown that if no more iron dust is inhaled the iron oxide is gradually eliminated from the lung parenchyma and the shadowing will be reduced. Histologically, in the lungs there is much amorphous pigment in the periarterial and peribronchial lymphatic channels and the alveolar sacs, but no fibrosis has been found either in lymph glands or in lung tissue.

The Registrar-General's Supplementary Report on Occupation Mortality in I93I shows that there were 123 deaths among $11,45^{2}$ welders, compared with an expected 161 on the basis of age rates for all males. This evidence alone shows conclusively that iron oxide is an inert dust in the lungs. Other dusts which produce radiological shadowing in industry are tin oxide, the atomic weight of tin being II7.8, and barium, which has an atomic weight of r37.4. Because of the higher atomic weight of these two metals, the shadowing is more dense than in the case of siderosis and the conditions have been called, respectively, stannosis and baritosis.

Silver polishers use rouge, which is iron oxide, and are, therefore, exposed to a dust which contains a mixture of silver and iron. X-rays of silver polishers' lungs show the typical picture of reticulation. This is partly caused by iron oxide, and also in part caused by the intra-vitam staining of the 
elastic tissue of the arterial, alveolar and bronchial walls with silver oxide.

\section{Sensitivity Reactions}

There is little doubt that certain dusts of organic origin will produce a sensitivity reaction in the lung, which results in attacks of shortness of breath with a wheeze. This is probably the result of oedema of the bronchial wall and over-activity of the bronchial mucosal glands, producing narrowing of the smaller bronchioles. Pollens and the dust of wheat and grain are notorious for giving rise to this condition, and it therefore occurs mostly in millers and bakers. Hair dandruff will also produce such a reaction, and this will be found in hairdressers and those concerned with the care of horses or other fur-bearing animals, including furriers. The complex salts of platinum also cause an irritation to the nasal passage, throat and trachea. The symptoms are repeated sneezing, followed by tightness of the chest, shortness of breath and a wheeze. The symptoms persist as long as the worker remains in the factory, but about half an hour after he has left they subside. Radiograms reveal no abnormality.

Organic vegetable dusts have been reported from all over the world as producing pulmonary reactions. Farmer's lung, which was first described in England in 1932, occurs particularly in haymakers, but it has been described in all harvest workers and was in Scandinavia called Thresher's lung. A similar reaction has been described in tea tasters, and the disease 'broken wind ' in horses is probably a similar disease.

In the earlier stages of the war a disease was found in those who worked with bagasse, which is sugar cane after the sugar has been extracted. Respiratory disease is common in cotton workers and has been called byssinosis. In all these diseases the vegetable material seems to be contaminated by fungi, and many writers have ascribed the disease to these organisms. They are consistently present in all the dusts, but they are probably not the immediate cause, though it is possible that by producing toxic substances they indirectly contribute to the aetiology of the condition.

Of these diseases, that caused by cotton is by far the most important in this country. As early as 1818 Jackson drew attention to the fact that those who worked in the cotton industry, particularly card-room workers, suffered from a characteristic respiratory disease. Foreign literature on the condition is scanty, but it has been reported from both Germany and the United States. The exact method by which the disease is produced is still a matter of uncertainty. The protein fraction of card-room dust is capable of producing inflammatory lesions in animals and the characteristic course of the disease is suggestive of an acquired hypersensitivity, but the primarily toxic qualities of the protein prevent the condition from being regarded as purely allergic.

Cotton arrives in England in tightly compressed bales and it is the workers who are engaged on the earlier processes who are involved; those who open the bales and those who work on the carding engines, particularly the strippers and grinders. After working for several years in the dusty atmosphere the patient begins to sneeze and develop a dry and irritating cough, with a tight feeling in the chest and restricted intake of breath. To start with the symptoms are temporary and pass off in a few days, but they return after a short absence from work, such as a weekend, and it is for this reason that the condition is sometimes called 'Monday morning fever,' ' mill fever' and ' factory fever.' Disablement and incapacity for work does not occur until the man has been exposed to the dust for Io years or more, when the symptoms may become more severe and persistent, and the patient develop attacks of shortness of breath associated with a wheeze, shallow breathing, cough and a small amount of sticky, mucoid sputum. The disease progresses and finally arrives at an incurable stage so that many of these workers die before the age of fifty from right-sided heart failure.

The physical signs and X-ray findings are in no way different from those associated with chronic bronchitis and emphysema. Necropsies also reveal no specific changes in the lung. Death frequently results from cor pulmonale.

\section{Silicosis}

Silicosis is a fibrosis of the lung caused by the inhalation of free crystalline silica or quartz particles. It is the most disabling of all the dust diseases, yet the precise method by which the silica causes the disease is not yet established. It was thought to be mechanical in origin, being caused by the movement of the lung on the sharp crystals, until in 1932 Gardner, in Saranac Lake laboratories, showed that carborundum (silicon carbide) crystals, which are just as sharp and hard as those of silica itself, do not produce the disease in animals. It was then suggested that silica went into solution in the phagocytes forming silicic acid and when this was released, as a result of destruction of the phagocyte by infection, either tuberculous or non-tuberculous fibrosis resulted. This is known as the Solubility Theory. It seems most improbable, since silicic acid is one of the most innocuous of substances it is possible to inject into the human body. However, in 1933 Kettle showed that by mixing iron oxide with the silica the amount of fibrosis produced in the lung was 
greatly reduced, and the similar finding with aluminium oxide has led to it being used with the idea of treating and preventing silicosis. There is no doubt that mixture with other substances has a profound influence on the reaction produced in the lung, and as iron and aluminium slow down the process, so alkali appears to accelerate it. This is of great importance in industry, since no industrial dust is a pure dust and, therefore, it is frequently difficult to forecast what effect it will have. It seems certain that the causation of the disease results from some physico-chemical process around freshly fractured quartz crystals.

The classical pathological picture of silicosis is that of a discrete nodular fibrosis. The fibroblasts forming the nodule have a typical laminated appearance, which causes the structure of the nodule to resemble the cut surface of an onion. The nodules gradually increase in number and tend to drift outwards towards the pleura. In the later stages the nodules, particularly in the upper parts of the lung, conglomerate and form massive areas which tend to undergo degeneration.

Pure silicosis occurs in metalliferous miners, granite quarry workers, metal grinders and sandstone masons. The most rapidly developing variety of silicosis which has been reported was that encountered in workers engaged in the manufacture of scouring powders, which are a mixture of silica, soap and alkali. Women died within a period of three years.

The symptom caused by the disease is shortness of breath. This may be exaggerated by catarrhal bronchial infection which leads to cough with sticky sputum and, later, tightness of the chest and a wheeze. There is no doubt that pulmonary tuberculosis is a frequent complication of the disease-it predisposes to the development of silicosis, and silicosis equally predisposes to tuberculosis. The respiratory impairment can be demonstrated by the reduced vital capacity, maximum breathing capacity and increased residual air, as well as a reduction in the blood oxygen tension. Radiograms of the chest show, first, reticulation, then nodulation and, finally, massive shadowing. Later, opacities develop in the mediastinal glands, which become outlined and look like a bunch of grapes.

Yearly X-rays can be taken of the workers and, should the disease be seen to be progressive or should there be the least suggestion of the development of massive shadowing, they should be removed from exposure to dust at a time when they will have suffered no disability and will then be able to engage in alternative employment.

\section{Pneumoconiosis of Coalworkers}

Pneumoconiosis of coalminers is the most im- portant dust disease in the British Isles. The existence of the disease in South Wales has beeR known for a century. Thackrah, in 1831 , recog - . nized that colliers were liable to develop ' miner' asthma,' and the condition was subsequentl $\vec{f}$ described as the ' scourge of the mines.' With thE् introduction of compensation certificates, the in $\overline{\overline{0}}$. cidence has rapidly increased. The dust inhale by coalminers is a mixture of coal, silicates, an silica. There is no doubt that the quantity of duse inhaled has an important bearing on the incidence of the disease in different mines. In the past it has been generally thought that the disease was morf్ readily caused by anthracite than by other coas dusts. It has, however, been shown that the an 3 thracite mines have been badly ventilated and therefore, the quantity of dust inhaled by workers in them has been high; a fact which probabl explains the high incidence in those mines in the past. With the installation of better ventilationd which has coincided with the greater development of mechanical methods in bituminous and steam. coal mines, the quantity of dust in the atmosphere of the different categories of mines have approxic mated more close to each other, so that there wouls appear not to be a great difference in incidencesin the different categories of mines.

When the dust is inhaled into the lungs forms characteristic coal foci. A delicate fibrọis develops round these foci and this may proceed to the development of hard collagen tissue. The gradually fade into an unaffected lung tissue Around these coal foci develop areas of honey combing or focal emphysema. This focal emphy $\overrightarrow{0}$ sema is the characteristic picture of the disease and it is this destruction of healthy lung and its replacement by fibrosis and focal emphysema which causes the disability in the disease.

Superimposed on this histological picture of simple pneumoconiosis, there may be fibrosis resulting from infection, either tuberculous or non tuberculous. These massive areas of fibrosi occur principally in the upper halves of the lungs. especially in the posterior segment of the uppex lobe and the apical segment of the lower. The are composed of dense, black tissue of a harch. rubbery consistency, and they usually have a smalf cavity in the centre which may contain some black liquid. Many workers think these lesions ar essentially tuberculous in origin. This may be sợ but if they are, they run an attenuated course ans, both histologically and clinically, there is fres quently no evidence of tuberculosis. At the present time, miners have regular routine $\mathrm{X}$-rays of their lungs and the disease can, therefore usually be detected before any symptoms de्d velop.

The essential symptom resulting from 
destruction of normally-functioning alveoli is shortness of breath. To start with, this may occur only on exertion, but it becomes gradually progressive. Later the men may develop a cough from bronchitis. When this is associated with the breaking down of large areas of diseased lung there may be sputum, and if the black fluid from the centre of an area of massive fibrosis is coughed up, the symptom has been called melanoptysis. When the first radiological changes are seen, it is unlikely that there will be any abnormal physical signs but, as the disease develops, the patients become dyspnoeic and, eventually, orthopnoeic. They may get clubbing of their fingers, their chests become barrel-shaped, and respiratory movements are poor. Sometimes there is flattening of the chest below the clavicle, and often hyper-resonance over the bases. The air entry may become diminished and, when bronchitis develops, coarse crepitations are heard throughout the lungs.

In the early stages the X-ray appearances are of a fine net-work, sometimes sharp and lace-like in pattern, or, more often, blurred in appearance, scattered throughout the whole of both lung fields, and well marked at the periphery. As the disease becomes more advanced, multiple, discrete shadows, 2-3 $\mathrm{mm}$. in diameter, are scattered throughout the lung fields. These later may coalesce or conglomerate, so that massive shadows develop. When these occur there is usually evidence of basal emphysema. As the disease progresses, the vital capacity and maximum ventilatory capacity are usually below normal, and the residual air is increased. Exercise tolerance tests are also below standard. It is frequently found that when these symptoms are present there is a rising blood sedimentation rate. This is probably the result of superimposed infection, which may be either a catarrhal bronchitis or pulmonary tuberculosis. If a man is removed from exposure to the dust before massive conglomerations have developed, the disease does not progress but, when these lesions have developed, it nearly always pursues a slow course, but one which may progress rapidly, even if the man is no longer in contact with the dust.

Once a diagnosis has been made, the patient should be removed from further exposure to coal dust. If this is done in the early stages he will be able to do full-time work in other industries, but if it is left until the disease is far advanced he will become a respiratory invalid. Inhalations of aluminium dust have been used to attempt to cure the disease. It is impossible to see what beneficial effect these may have, and there is certainly no scientific evidence that they produce any change in the course of the disease, though, frequently, the workers express the faith that they are better.

\section{Silicates}

Silicate dusts are widespread in industry and their effect on the lung is variable. Asbestos and talc produce severely disabling diseases, and even death-whereas it takes many years for china clay and mica to produce any noticeable changes and then they are slight.

Asbestos is, therefore, much the most important of these substances from the health point of view. It is essentially iron-magnesium-aluminium silicate but, mineralogically, there are two main types. Hornblende or amphibole, in which iron is present in large quantities and which is frequently blue in colour. It is produced exclusively in South Africa and is widely used in this country. Chrysotile is white and in it magnesium predominates; it is mined in Canada, Rhodesia, Transvaal, Australia, Italy and Russia. The word ' asbestos' is derived from the Greek and means ' unconsumable.' The crushed rock can be separated to an extreme degree of fineness and, therefore, its needle-like crystals can be carded, spun into yarn and woven into cloth. Asbestos is also used extensively for thermal insulation. It is also ground and mixed with cement and plastics to make insulating slabs, boarding, and brake linings. The dust produced in these various processes is mostly less than $5 \mu$ in diameter.

The first recorded case of asbestosis was reported from Charing Cross Hospital in 1907, seven years after the patient's death. The account was a full story of the disease. The patient died at the age of 34 , being the last survivor of ro men who had worked in a carding room where asbestos was being carded. They had all died at about the age of 30 with respiratory disease. The recorded patient had worked in the carding room for $\mathrm{I}_{4}$ years. Necropsy revealed extensive, diffuse pulmonary fibrosis and the lungs were found to contain asbestos bodies. After this, many cases were recorded, but it was not until 1930 that active efforts were made to suppress the disease by the introduction of exhaust ventilation.

Clinically, the striking symptom is shortness of breath of gradually increasing intensity. There is often a dry cough. Clubbing of the fingers is frequently a prominent physical sign but, in the lungs in the early stage of the disease, crepitations are few or absent, but later râles throughout the lungs develop. Radiologically, the most characteristic feature is the 'shaggy' outline of the heart shadow, but the fine fibrosis may cause a ' ground glass ' appearance throughout the lung fields and the subpleural thickening may be evident, particularly in the interlobar fissures. Examination of the sputum will reveal the presence of asbestos bodies.

Pathologically, pleural adhesions are extensive and dense, and there are often thick, subpleural 
plaques of fibrous tissue. There is increased consistency of the lung and there may be large areas of fibrous condensation which is tough and stony hard. Emphysema is extensive but localized to the lower and apical parts of the lungs. Pneumothorax sometimes occurs. Histologically, there is generalized fibrosis with diffuse thickening of the alveolar walls, while throughout the lung tissue characteristic asbestos bodies may be seen.

In recent years, patients with asbestosis have shown no particular susceptibility to develop pulmonary tuberculosis, but the incidence of carcinoma appears to have been about 15 per cent. This is much higher than in the general community and it is of particular interest that it is divided equally between the sexes.

The patients usually die from right-sided heart failure. Throughout, this disease is much more a clinical one than a radiological one-which is a marked contrast with silicosis. While the mechanism which produces silicosis is still undecided, there is little doubt that in the case of asbestosis it is mechanical in origin, resulting from the trauma and mechanical irritation produced by a combination of the long, needle-like crystal, and the rhythmic movement of the lung and heart.

Talc, or french chalk, is a silicate somewhat similar to asbestos. It is a hydrated-magnesium silicate. Mineralogically, it is known as steatite, tremolite, anthophylite and asbestine. It is used in industries as a filler for paper, soaps and paints; for leather dressing, the manufacture of rubber motor tyres, making electric switchboards, and for heat insulation for steam pipes. Since 1896 it has been known to be capable of producing lung disease, but it has only been in recent years, and especially in the past 10 , that it has been appreciated that there was any considerable number of cases. Asbestine being a crystalline substance of much the same shape as asbestos, it is not surprising that a disease clinically similar to asbestosis results; a feature of the histology being the presence of bodies similar to asbestos bodies. The principle difference in the two diseases is the slower rate of progress which occurs in talcosis.

China clay or kaolin, is a hydrated silica of aluminium, and is at the present time an important export from this country to the United States. It is used extensively in the manufacture of fine art paper, but also is an important ingredient in china and earthenware pottery, and is used in the making of cotton cloth, paint and soap. The largest deposits of china clay in the world are found in Cornwall. Workers have been engaged in the industry throughout their lives and throughout the century and have not appeared to suffer any ill effects. During the past ro years, however, radiological surveys have shown that $\mathrm{X}$-ray changes do occur after many years of exposure to the dust. These consist of fine mottling, most $\stackrel{\mathbb{Q}}{\complement}$ marked in middle zones and at the bases. Massive $c$ shadows have also been found in a few workers. $\overrightarrow{\vec{N}}$ These workers have few symptoms and it is? probable that the dust does not produce great, if $\frac{\mathrm{C}}{\mathrm{O}}$ any, disability.

Silimanite is an aluminium silicate found in India and used as a refractory material in the $\unrhd$ manufacture of porcelain. It breaks into pris- $ळ$ matic crystals and not needles like asbestos. While $\overrightarrow{0}$ there is some evidence that radiological changes $\vec{\overrightarrow{ }}$ may result from exposure, there is little evidence $\vec{\omega}$ that it produces a disabling disease.

Mica, or shale, is an aluminium-magnesium silicate which is widely distributed in nature, and is extensively used commercially. Diatomaceous earth-also known as diatomite, kieselguhr and ferina fossil-and Tripoli are hydrated, amorphous minerals of organic origin and generally considered to be varieties of opal. All these substances $ᄋ$ have been recorded as producing $X$-ray changes, and it is probable they all produce some pulmonary fibrosis. However, the disability that results is slight.

\section{Carcinoma}

In the Middle Ages, Agricola and Paracelsus drew attention to the associationship of lung disease and mining in the mountains of Saxony. They called it the ' mountain disease.' In the last half of the last century it became known that about three-quarters of the miners in this area developed, and died from, a pulmonary disease after about 20 years work in the mines; during the present century this disease has been shown to be lung cancer.

The main ores in the area are the sulphides and arsenides of nickel and cobalt. In the southern side of the area there is a high content of pitchblende and radium. The disease has, therefore, been ascribed variously to arsenic, cobalt and radioactivity. But carcinoma of lung has also been shown to occur in workers engaged on refining $\frac{0}{7}$ nickel, in which process there is escape of much $D$ dust which has a high content of arsenic. It has also been shown that the incidence of carcinoma in $N$ chemical workers, manufacturing arsenical sheepdips, is twice as high as in the normal population.

It is also possible that arsenic may account for the world-wide increase in the mortality rate for carcinoma of lung in males, since cigarette fume contains 2.5 to $3.5 \mathrm{mg}$. arsenious oxide per cubic meter.

There is also much evidence that monochromates are carcinogens: 64 per cent. of a group of workers in seven chromate plants in the United States died from cancer of the lung, compared with 
Statistics of a town where manufacture of arsenical sheep-dip was principal industry.

(Hill, 1948)

Percentage Deaths

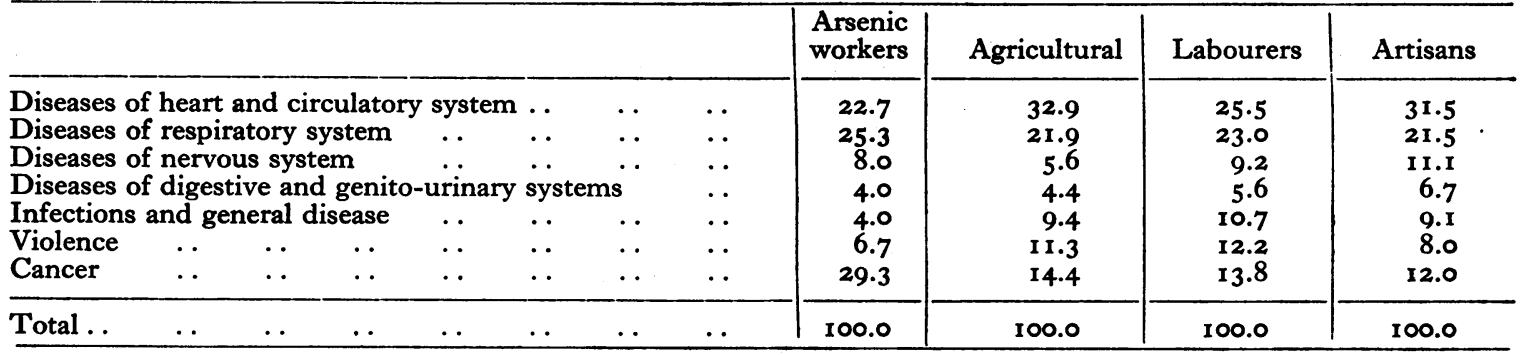

Percentages Cancer Deaths by Years

\begin{tabular}{|c|c|c|c|c|c|c|c|c|}
\hline & & & & . & & & Arsenic workers & $\begin{array}{c}\text { Other occupation } \\
\text { groups }\end{array}$ \\
\hline $\begin{array}{ll}1910-19 & \ldots \\
1920-29 & . \\
1930-43 & \ldots\end{array}$ & $\begin{array}{l}\cdots \\
\cdots \\
\cdots\end{array}$ & $\begin{array}{l}\cdots \\
\cdots \\
\cdots\end{array}$ & $\begin{array}{l}\cdots \\
\cdots \\
\cdots\end{array}$ & $\begin{array}{l}\cdots \\
\cdots \\
\cdots\end{array}$ & $\begin{array}{l}. \\
.\end{array}$ & $\begin{array}{l}\cdots \\
\cdots \\
\cdots\end{array}$ & $\begin{array}{l}28.6 \\
37.6 \\
31.3\end{array}$ & $\begin{array}{l}11.1 \\
14.5 \\
13.0\end{array}$ \\
\hline Total & . & $\ldots$ & $\ldots$ & $\ldots$ & .. & .. & 29.3 & 12.9 \\
\hline
\end{tabular}

Percentages by Occupation in Arsenic Workers

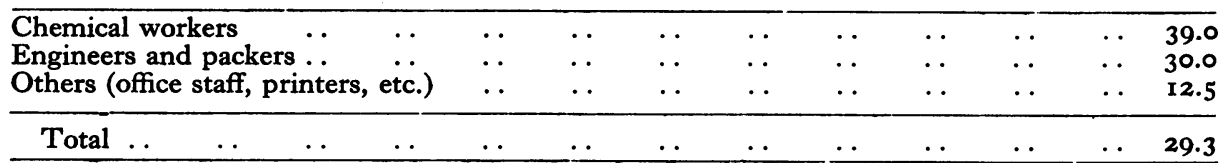

9 per cent. in other occupations. Similar findings have been recorded from Germany and from the British Isles.

Work in all parts of the world has shown a high incidence of carcinoma in asbestos workers. It is as high as 15 per cent. in patients with asbestosis. Many asbestos workers are women. The incidence of carcinoma in them is as high as in men. This is a sharp contrast to the findings in the rest of the population; of the 17,272 deaths from carcinoma of lung in England and Wales in 1955, 14,821 were men, and only $2,45 \mathrm{I}$ women. The sex similarity, therefore, in asbestos workers is further evidence in support of this substance being a carcinogen.

\section{NOTICE OF SPECIAL INTEREST TO SUBSCRIBERS:}

'WHY NOT HAVE YOUR COPIES OF THIS
JOURNAL BOUND INTO YEARLY VOLUMES?'

You can have your twelve monthly issues fully bound in dark green pin head cloth. lettered in gilt on spine with name of Journal, Volume Number and year, complete with index at front, for 22s. 6d. post free. A limited number of out of print journals are available to bind into volumes and make your library complete. Price on application giving details of issues required to complete back volumes.

THE FELLOWSHIP OF POSTGRADUATE MEDICINE 60 PORTLAND PLACE, LONDON, W.I
WHY NOT

HAVE YOUR

JOURNALS

BOUND? 